\title{
Literatura infantil y pasado vergonzante: espacios y aconteceres entre generaciones*
}

Children's Literature and Shameful Past: Spaces and Events Between Generations

Literatura infantil e passado vergonhoso: espaços e eventos entre gerações

\author{
Martha Cecilia Herrera-Cortés** (iD) https://orcid.org/0000-0003-4170-7822 \\ Carol Juliette Pertuz-Bedoya*** iD https://orcid.org/0000-0003-2184-0933
}

Doi: 10.17227/rce.num78-8245

Para citar este artículo: Herrera Cortés, M. C. y Pertuz Bedoya, C. (2020). Literatura infantil y pasado vergonzante: espacios y aconteceres entre generaciones. Revista Colombiana de Educación, 78, 43-71. http://doi.org/10.17227/rce.num78-8245

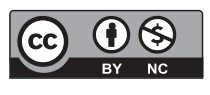

Recibido: 26/07/2018

Evaluado:17/05/2019

* El artículo presenta resultados de la investigación adelantada en la beca-pasantía de Jóvenes Investigadores e Innovadores de Colciencias en el marco de la convocatoria 761 de 2016, cofinanciada por la Universidad Pedagógica Nacional y adelantada en el grupo de investigación Educación y Cultura Política bajo el título "Configuraciones de la memoria intergeneracional en la literatura infantil. Aportes a los debates sobre la memoria pública en Colombia". Se inscribió a los proyectos de investigación "Educación y políticas de la memoria: por una pedagogía más allá del paradigma del sujeto víctima" (DPG-418-15) y "Programa de investigación y formación Configuración de subjetividades y constitución de memorias sobre la violencia política en América Latina" (DPG-449-17).

** Doctora en Filosofía e Historia de la Educación, Universidade Estadual de Campinas, Brasil. Profesora catedrática, Facultad de Educación, Universidad Pedagógica Nacional. Correo electrónico: malaquitalO@gmail. com, mherrera@pedagogica.edu.co

*** Maestría en Estudios en Infancias. Profesora ocasional tiempo completo, Facultad de Educación, Universidad Pedagógica Nacional. Correo electrónico: carolpertuz(a)gmail.com 


\section{Resumen}

¿Cómo se narra la violencia política en la literatura para niños? ¿Cuáles son los sentidos del pasado que se ponen en juego en estas narrativas? ¿De qué manera los vínculos generacionales permean la escritura de sus autores? A través de estas preguntas este artículo de investigación pretende explorar las formas como se configura el entre generacional en la literatura infantil colombiana referida al pasado vergonzante. Se analizan algunas obras de Triunfo Arciniegas, Jairo Buitrago y Francisco Montaña para mostrar sus configuraciones con base en preguntas por el tejido intergeneracional que impregna su escritura y sus formas de narrar la violencia política. En términos metodológicos, se entrecruzan análisis que incluyen aspectos literarios y aspectos históricos que recogen elementos de lo político y de lo social. Con el análisis de los trabajos de los autores propuestos en este artículo se observan herencias recibidas en las que operan apuestas por el sostenimiento o el cambio del orden social y las condiciones de violencia política que emergieron en el marco de una democracia restringida desde la década de los setenta. También se encuentran los legados por transmitir a las nuevas generaciones, en los que se ponen en juego miradas hacia el pasado vergonzante desde los referentes propios de los escritores en el presente. Sobre la base de este inter/entre generacional los escritores construyen en sus obras apuestas para la transformación del porvenir en las que la mirada hacia el pasado forma parte fundamental por cuanto este es revisitado y resignificado. Los hallazgos muestran que la literatura infantil, como artefacto cultural, participa del mundo social y político ofreciendo posibilidades de ruptura con el pasado vergonzante y de construcción de sentidos distintos.

\section{Palabras clave}

literatura infantil; memoria; educación; violencia; brecha generacional

\section{Keywords}

children's literature; memory; education; violence; generation gap
How is political violence narrated in children's literature? What are the senses of the past underlying these narratives? How do generational links permeate the writing of their authors? Through these questions, we intend to explore the ways in which the betweengenerations is configured in Colombian children's literature referring to the country's shameful past. We analyze some works by Triunfo Arciniegas, Jairo Buitrago, and Francisco Montaña to show their configurations of the between-generations based on questions about the intergenerational fabric which permeates these authors' writing and their ways of narrating political violence. In methodological terms, the analysis includes literary and historical aspects considering political and social elements. Based on the analysis of the works proposed in this article, we found some inheritances in which authors bet on the support or change of the social order and the conditions of political violence that emerged within the framework of a restricted democracy since the seventies. We also found legacies to be transmitted to the new generations, in which stares towards the shameful past are put into play from the referents of writers in the present. Because of this generational inter/between, the writers build in their works wagers for the transformation of the future in which a look to the past is a fundamental part because it is revisited and resignified. The findings show that children's literature, as a cultural artifact, participates in the social and political world, offering possibilities of breaking away from the shameful past and the construction of different senses about the past.

\section{Resumo}

Como a violência política é narrada na literatura infantil? Quais são os sentidos do passado que são postos em jogo nessas narrativas? Como os links geracionais permeiam a escritura de seus autores? Por meio dessas perguntas, este artigo de pesquisa visa explorar as maneiras pelas quais configura-se o entre geracional na literatura infantil colombiana referida ao passado vergonhoso. Alguns trabalhos de Triunfo Arciniegas, Jairo Buitrago e Francisco Montaña são analisados para mostrar suas configurações com base em perguntas sobre o tecido intergeracional que permeia sua escrita e seus modos de narrar a violência política. Em termos metodológicos, análises que incluem aspectos literários e históricos que pegam elementos dos aspectos políticos e sociais estão entrelaçadas. Com a análise dos trabalhos dos autores propostos neste artigo, são observadas as heranças recebidas nas quais operam apostas pelo apoio ou mudança da ordem social e das condições de violência política que surgiram no marco de uma democracia restrita desde a década de Setenta Há também os legados a serem transmitidos às novas gerações, nos quais os olhares sobre o passado vergonhoso são postos em jogo pelos referentes dos próprios escritores no presente. Com base nesse inter / entre gerações os escritores constroem em suas obras apostas para a transformação do futuro em que o olhar para o passado é uma parte fundamental, porque é revisitado e ressignificado. Os resultados mostram que a literatura infantil, como artefato cultural, participa do mundo social e político, oferecendo possibilidades de romper com o passado vergonhoso e construir diferentes significados.

\section{Palavras-chave}

literatura infantil; memória; educação; violência; conflito de geraçōes 


\section{Introducción}

Desde la década de los años setenta los países latinoamericanos han experimentado momentos de agudización de la violencia política. En el Cono Sur esta violencia se intensificó por cuenta de las dictaduras; en Centroamérica, de las luchas revolucionarias, y en Colombia y otros países de Suramérica, por cuenta de las fuertes restricciones a la democracia. Las "medidas de excepción" implementadas desde ese periodo y la complejización del panorama político y social arrojaron como saldo un pasado vergonzante signado por la violencia que ha dejado huellas en quienes lo vivieron siendo jóvenes y adultos, y que, a su vez, han legado los vestigios a sus hijos y nietos. Bajo los supuestos de la herencia y de la transmisión emerge la pregunta por las formas como los escritores de literatura infantil que vivieron la violencia política del pasado reciente en el país proponen narrativas que dialogan con diversas apuestas sobre el orden social, interpelados tanto por el pasado como por su propio presente.

En la primera parte del artículo se sitúan las relaciones entre la educación, la configuración intergeneracional de memorias y los pasados vergonzantes y se muestra la literatura infantil como un lugar en el que es posible observar el espacio y el acontecer entre generaciones. En la segunda parte se analiza el trabajo de tres escritores colombianos: Triunfo Arciniegas, Jairo Buitrago y Francisco Montaña. Inicialmente, se presenta un acercamiento con características biográficas para comprender las herencias recibidas y sus vínculos con el pasado, los sentidos que le otorgan a su escritura en el tiempo presente y sus apuestas en los legados por transmitir a las nuevas generaciones. Luego, con miras a la aproximación a las formas de narrar la violencia política en estos tres escritores, se abordan seis obras (dos de cada uno) con base en tres aspectos: las matrices discursivas y el tipo de narrativa construidas por los escritores; las formas de enunciar la fuente de la violencia; y el rastreo de elementos comunes en las seis obras. En la tercera parte del artículo, se exponen potencialidades de esta literatura para el trabajo de memoria en clave intergeneracional en diferentes escenarios de formación y socialización. Finalmente, se elaboran unas breves conclusiones con base en lo planteado.

En términos metodológicos, el análisis incluye aspectos biográficos de los escritores, aspectos literarios situados en la obra y aspectos del contexto histórico del país que recogen elementos de lo político y de lo social. Así, la lectura que se hace de las obras tuvo en cuenta elementos intra- y extratextuales propios del análisis de contenido, así como elementos de la teoría de las relaciones transtextuales de Gérard Genette, de manera particular la architextualidad, la paratextualidad y la metatextualidad, en un entrecruzamiento de criterios estéticos e históricos. Asimismo, además 
del reconocimiento de las obras en su contenido literario, se les considera artefactos culturales capaces de generar cambios en la cultura, en arreglo a modificaciones en los modos de representación del pasado y del presente.

\title{
Educación, memoria y pasados vergonzantes: consideraciones teóricas y metodológicas
}

\author{
El achicamiento. El ensanchamiento. El lugar. Los márgenes. El \\ trazo. La mancha en la hoja. El gesto. Mi gesto. El gesto de cada \\ uno. La educación se trata de todas esas cosas, aunque a veces \\ nos quieran hacer creer que trata de otras.
}

Graciela Montes, Buscar indicios para construir sentido

La educación, de acuerdo con Bárcena (2012a), "concierne a una transmisión entre generaciones en la filiación del tiempo" (pp. 15-16). Un entre que se puede comprender, o bien como espacio, o bien como acontecer. En el primer caso, el entre da cuenta de las distancias que se achican o se ensanchan — para seguir las palabras de Graciela Montes-, se conectan a través de puentes o se incomunican por brechas que se presentan (falsamente) insondables; de las asimetrías y las discontinuidades de los tiempos —el tiempo joven y el tiempo adulto- (Bárcena, 2012b). En el segundo caso, los aconteceres sitúan aquello que permite la construcción de tales puentes o la apertura de las mencionadas brechas, lo que se transmite, las herencias, lo que se asume o lo que se abandona en la introducción de los más jóvenes en el universo de la cultura, las interpelaciones de los recién llegados a los establecidos, la puesta en juego de los tiempos múltiples que convocan el encuentro y el desencuentro de niños, jóvenes y adultos.

La educación, así entendida, plantea la necesidad de situar una mirada que permita comprender los modos como el contrato generacional entre los mayores y las nuevas generaciones persiste y se despliega en la complejidad del encuentro/desencuentro en un tiempo constituido por la abigarrada relación pasado-presente-futuro que se entreteje en complejas temporalidades. Desde esta perspectiva, el niño se reconoce como sujeto que interpela al adulto y lo moviliza a pensar-se desde su responsabilidad ética situada en varias dimensiones: en las formas de comprender el pasado desde el presente para dotarlo de nuevos sentidos en su esfuerzo por presentarlo/representarlo/re-crearlo para los recién llegados; en las formas de enunciar al otro o a lo otro; $y$ en el ofrecimiento, a las nuevas generaciones, de "un mundo cuya responsabilidad asumen [los adultos] aunque ellos no son quienes lo hicieron y aunque, abierta o encubiertamente, preferirían que ese mundo fuera distinto" (Arendt, 1996, p. 201). De este modo, por 
cuanto el adulto precede al niño, le corresponde "conocer el mundo y ser capaz de darlo a conocer a los demás" (1996, p. 201), sin perder de vista la cita de cada generación con el pasado.

Esa relación, de orden educativo, de los establecidos con los nuevos, se erige como un asunto que atraviesa las barreras de lo histórico para instaurarse como constitutivo de la vida, como una tarea humana. La infancia se vislumbra, entonces, como una configuración relacional que entrama la temporalidad de la memoria —-pasado, presente y futuro-, por lo que, además de mantener el hilo de la vida y el vínculo institucional, guarda claves fundamentales para comprender el vínculo social, la configuración de la memoria personal o colectiva como pretérito que permanece por el paso de generación en generación y las imbricaciones o los distanciamientos de la historia y la memoria: la consolidación, el desplazamiento, la discusión, la interrupción o la destrucción (Ricoeur, 2000).

Si es la generación adulta la que asume la inmersión del niño en la cultura, entonces, estos procesos de configuración de memorias demandan de parte del adulto una responsabilidad ética, ligada a una del orden político y pedagógico - que no tiene que ver aquí con lo moralizante, como suele asumirse en el campo de la literatura-; pues, si frente a los nuevos es necesario decir que los hechos ya están dados, el reto es trabajar en el sentido de lo no acontecido, lo que no está "fijado de una vez para siempre" (Ricoeur, 2000, p. 492). En ese reto, se abre la posibilidad de narrar e interpretar de otro modo el pasado, lo que justifica la pregunta por el espacio y el acontecer entre generaciones, en relación con acontecimientos situados - en este caso, de violencia política desde la literatura infantil colombiana-, como una forma de comprender la existencia de una idea del pasado (vergonzante) como carga o como posibilidad de ser y de transformación hacia el futuro.

Por lo anterior, cobra relevancia pensar en las formas como se configura el inter/entre generaciones como posibilidad de acceso a la comprensión del mundo y preguntarnos, ante las producciones culturales que se suponen distantes entre adultos y niños, ¿a partir de qué estrategias es posible situar el diálogo intergeneracional para la construcción de sentidos sobre el pasado, no siempre ejemplar, construido en torno a acontecimientos vergonzantes? ¿Cómo entablar el diálogo con los niños sobre el pasado violento? ¿De qué manera explorar las huellas, en lo social, del pasado en el presente? ¿Cómo recibir la herencia, pero sometiéndola a discusión y revisión?

Con todo, el entre generacional se constituye como pista para comprender, en la literatura, las particularidades culturales de la memoria que se enuncia y se hace relato, a partir de lenguajes exentos de la veracidad del dato histórico que permiten dilucidar la imbricación entre memoria e 
historia. Así, frente a los interrogantes planteados en la apuesta investigativa de la que da cuenta este artículo, se reconoce en la literatura infantil un escenario importante para la mirada del entre generaciones, por cuanto constituye un lugar desde el cual se posibilita el encuentro/desencuentro entre niños, jóvenes y adultos, quienes se suponen diferentes en la figuración de mundos separados, artificialmente creados y diametralmente opuestos, en virtud de ser más nuevos o más viejos en el mundo. Estos encuentros y desencuentros se producen tanto en el universo de la obra literaria como en el plano de la realidad de escritores e ilustradores y lector, pues la literatura infantil da cuenta de formas de simbolización y significación del mundo hechas por los adultos cuya clasificación apunta hacia generaciones distintas o propias, un escenario de encuentro entre-generaciones de lectores o entre un otro (adulto que escribe, recrea, representa, simboliza) y el lector (público "infantil").

\section{El entre generaciones en tres escritores de literatura infantil colombianos}

Somos herederos, y eso significa que no nos relacionamos solo
con nuestros contemporáneos, sino con los que ya no están, nos
relacionamos con los ausentes y, más allá de nuestro presente
podemos pensar en los que vendrán, en los no nacidos.

FERNANDO BÁRCENA, El alma del lector. La educación como gesto literario

En este apartado se presenta la revisión del trabajo de tres destacados escritores de literatura infantil colombianos en diálogo con aspectos de sus trayectorias biográficas: Triunfo Arciniegas, ${ }^{1}$ Jairo Buitrago ${ }^{2}$ y Francisco Montaña. ${ }^{3}$ Inicialmente, el apartado se detiene en las maneras como el tejido intergeneracional permea la escritura de estos autores en el entramado del pasado, el presente y los horizontes de futuro; es decir, en sus vínculos con la generación anterior y las herencias que recibieron de esta, en su propia cita con el presente, y en las apuestas en los legados

1 Triunfo Arciniegas nació en 1957 en Málaga, Santander. Es magíster en Literatura de la Universidad Javeriana y especialista en Traducción de la Universidad de Pamplona. Fue maestro de escuela y actualmente se dedica a la escritura, la fotografía y la pintura. Ha publicado más de cuarenta libros.

2 Jairo Buitrago nació en Bogotá, en 1970. Escribe e ilustra libros para niños y ha sido ganador de prestigiosos premios en este campo. También investiga sobre cine. Actualmente reside en México.

3 Francisco Montaña nació en Bogotá en 1966. Es magíster en Teoría e Historia del Arte de la Universidad Nacional de Colombia. Realizó estudios de Filología e Idiomas y de Dramaturgia Cinematográfica. Ha realizado traducciones de prosa y poesía rusas. 
que hacen a las generaciones más jóvenes. Luego se discurre en torno a preguntas por las formas de narrar la violencia política y las apuestas de sociedad que les subyacen, con base en el análisis de dos obras de cada autor: El árbol triste (2005; 2009) y El último viaje de Lupita López (2011), de Triunfo Arciniegas; Camino a casa (2008) y Eloísa y los Bichos (2009), de Jairo Buitrago; y No comas renacuajos (2008) y El gato y la madeja perdida (2013), de Francisco Montaña.

En el primer abordaje propuesto se privilegia el análisis de elementos extratextuales de las obras, pues se ponen en diálogo los trabajos de los escritores con componentes de sus trayectorias biográficas, las cuales dialogan, a su vez, con la realidad política y social del país en diferentes periodos. Asimismo, se consideran en este apartado relaciones transtextuales del orden de la paratextualidad (por cuanto se retoman epitextos como declaraciones de los escritores en conversatorios y entrevistas) y de la metatextualidad (por cuanto se referencian algunos textos producidos por la crítica). En el segundo abordaje se concede mayor atención a elementos intratextuales, mientras que por el lado de las relaciones transtextuales se alude a elementos de la architextualidad (las matrices discursivas y los modos de enunciación) y de la paratextualidad (situados dentro del propio libro, como las dedicatorias, los epígrafes y los agradecimientos, entre otros peritextos).

\section{Herencias recibidas y legados por transmitir: acerca del tejido intergeneracional y sus huellas en la escritura}

Para comenzar, Triunfo Arciniegas —reconocido, entre otras obras, por Caperucita Roja y otras historias perversas $(1991 ; 2015)$, una subversión de los cuentos de hadas clásicos-, al referirse a sus últimos trabajos (entre ellos El último viaje de Lupita López, El árbol triste, El rabo de Paco y Yo, Claudia) señala que se encuentra en otro momento de su escritura: se ha desplazado del humor hacia el acercamiento a temas "más difíciles", como el poder, la guerra, la mutilación, el exilio, la vejez y la muerte. Por su parte, Sánchez (2009a) señala cómo el trabajo más reciente de este escritor se aproxima a "la etapa superior del humor: la ironía" (p. 22), en donde el desplazamiento de otras formas del humor, como la paradoja o la parodia hacia la ironía, representa un giro de la crítica sobre sí mismo hacia el cuestionamiento del discurso del otro.

En este momento de la escritura, con matices distintos del humor o su abandono para el abrazo de la nostalgia y el cuestionamiento a la crisis social, Triunfo Arciniegas "ingresa a un terreno nuevo, inexplorado, de reflexión - llamémoslo así, aunque suene pretencioso - de los grandes temas" (Sánchez, 2009a, p. 23). El escritor se encuentra atravesado por una sensibilidad a situaciones que, en un país en guerra, irrumpen en la

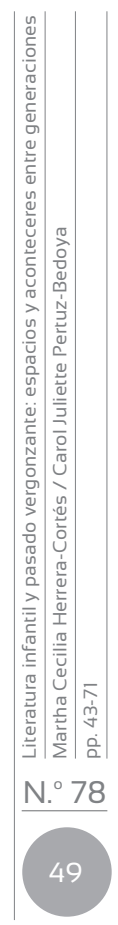


vida cotidiana para instalarse allí. Así, por ejemplo, Arciniegas relata que la historia de El árbol triste llegó en un momento en el que se encontraba interpelado por la circunstancia de estar fuera del país:

El árbol triste, más que la tierra, es el exilio lo que trata. Pero cuando uno se sienta a escribir no es ese el propósito, el propósito de uno es contar una historia. Yo vi un árbol. Lo vi, como lo ve el niño por la ventana, esa fue mi primera imagen, el niño viendo el árbol. Y ahí empecé a escribirlo. Lo que pasa es que yo estaba en México y está uno lejos de la casa... de todas maneras eso pega siempre duro, el despertarse en otro país, no es la misma cosa (Arciniegas en Reyes, 2016).

Esta vivencia que Arciniegas relaciona con El árbol triste se configura en un reclamo que encuentra eco en voces que comparten, para el caso, la experiencia del exilio. Así, el autor acompaña su libro con una dedicatoria: "Para Anabel Torres, lejos de casa"; esta poeta colombiana vive en el exilio desde la década de los años noventa. Arciniegas también insiste en este llamado a través de otras referencias que ejemplifican la temática que aborda su libro:

[...] lo que reclamo es el derecho a dormir en su propio nido. [...] En el 2000, exactamente, en un congreso en Cartagena, un escritor cubano me dijo "hace 27 años que no veo a mi madre", y no ve a su madre por un gobierno que no le deja volver. Los separó, los dividió [...] Y él murió dos, tres años después y jamás volvió a ver a su mamá. ¿Cómo una cuestión política nos jode la vida de esa manera? Sea de derecha, sea de izquierda, denuncio lo mismo (Arciniegas en Reyes, 2016).

En relación con el tema de permanecer o migrar, vale la pena señalar que los distintos momentos de agudización de la violencia política en Colombia han producido una diáspora de escritores y artistas; no obstante, muchos le han apostado a permanecer en el país. Con esta consideración, nueve escritores nacidos entre 1943 y 1963, entre ellos Triunfo Arciniegas, participaron en la recopilación de crónicas y relatos dedicados a algunas ciudades colombianas, editada por sm bajo el título Los días asombro: poética de las ciudades (2014). Según lo reseña Arciniegas, los nueve escritores

[...] decidieron su vida en el país: toda una declaración de principios. Han ido y han vuelto, pero su casa es Colombia definitivamente. Aquí se quedan. Otra sería la mirada si sus días y sus noches sucedieran en otro país y en otra lengua [...] han gozado y padecido la historia y presentan el testimonio de una época, de un país que sueña, que busca su acomodo. En su memoria, los salvajes días de la Conquista y la rapiña, la servidumbre de la Colonia, la sangre derramada en las guerras de la Independencia y en otras guerras descabelladas, y en su presente, tantos asuntos por resolver (Arciniegas, 2015, 18 de septiembre, párr. 2, 4). 
En la escritura de Arciniegas se refleja, entonces, la agrupación de la experiencia de una generación de artistas e intelectuales que, por las condiciones de violencia política del país, desde la década de los años setenta han sido forzados al destierro definitivo, o al ir y venir intermitente - como los personajes de $\mathrm{El}$ árbol triste-, o a ver partir a los otros. Este fenómeno y otros asociados a la guerra forman parte de las preocupaciones recientes del escritor en las que se lee una apuesta por contar a los niños "asuntos fundamentales, verdades ineludibles, preguntas eternas [que superen la] literatura rosa, falsa y mentirosa" (Arciniegas en Sánchez, 2009b, p. 59). Por ello, a la pregunta sobre el porqué de un libro para niños desde la ficción que toque la guerra, el escritor responde:

La guerra es parte de nuestra miserable vida cotidiana y sello ineludible de la realidad del país del Sangrado Corazón ${ }^{4}$ [...] Aquí los asesinatos se dan al por mayor [...] Se sabe de personajes con cien, doscientos o más muertos encima, que en el peor de los casos pagarán condenas ridículas y seguirán tan campantes, disfrutando de los bienes ajenos, mientras los pobres muertos siguen muertos y las viudas y los huérfanos se retuercen por siempre en la casa del dolor [...] Falseamos la realidad con palabras. La falsea el Gobierno, en primer lugar. Los asesinatos de muchachos inocentes por parte del Ejército son considerados "falsos positivos", a la guerra le dicen "conflicto", y a los desplazados los denominan "migrantes". Terminarán por confundirlos con "turistas". La guerrilla considera como "retenidos" a los secuestrados que mantiene como animales en corral. No se trata de un vicio exclusivo. En otras partes hablan de "fuego amigo", "misiles inteligentes" y "guerra preventiva" (Arciniegas en Sánchez, 2009b, p. 60).

Por su parte, Jairo Buitrago se ha aproximado en sus obras a varias cuestiones que dialogan con la realidad del país y que exploran el pasado en clave de comprender y develar una imagen de nuestro presente, sin renunciar a la fantasía. En sus libros hay referencias a problemáticas como el desplazamiento, la migración, el exilio y el desarraigo, la guerra, la desaparición y las ausencias, la pobreza y la desigualdad social, entre otras. Su tratamiento opera a manera de trasfondo histórico sobre el cual se exploran sentimientos como la soledad y el miedo, al mismo tiempo que la solidaridad, la amistad y la esperanza. Todo ello expresa, en últimas, formas de ser niño que habitan en el corazón del conflicto social y armado y en los márgenes de la infancia idealizada. En su escritura hay también elementos biográficos, algunos situados en la Bogotá de mediados de la década de los ochenta, como la toma del Palacio de Justicia que será el trasfondo histórico de uno de sus trabajos próximo a publicarse, la novela titulada Viendo fuego desde la ventana (Matiz, 2018, 12 de febrero, párr. 11). 
Para Buitrago el diálogo entre sus propuestas literarias y la realidad parece ineludible; sus trasfondos y referencias históricas tocan desde las guerras independentistas _El primer día (2010) y Los irlandeses (2017) _ hasta el actual proceso de posacuerdo en Colombia — Gabriela camina mucho (2016)_, pasando por la Guerra de los mil días — Retrato de niños con bayonetas (2017)—, la época de La Violencia y el Bogotazo (su hecho desencadenante), y la violencia de los ochenta, entre otros acontecimientos. Asimismo, el autor se ha aproximado al pasado reciente (o habría que decir pasado presente) de países como Chile _ Un diamante en el fondo de la tierra (2015a) — y México —Dos conejos blancos (2015b)_. Al respecto, el escritor señala:

Creo que al escribir libros también uno tiene su posición política, su posición sobre los temas sociales que lo afectan. Colombia, México y Argentina tienen una historia dolorosa de trasfondo, como muchos países latinoamericanos. Chile particularmente con la dictadura; Colombia con un conflicto armado que generó muchísima represión y México [...] años y años de represión política a muchos sectores (Buitrago en Espinosa, 2013, 11 de julio).

En estas múltiples referencias políticas en sus obras el escritor construye el punto de vista de los niños en situaciones cotidianas. Con todo, Buitrago no pierde de vista su lugar adulto, ni el de sus lectores:

Mis libros pueden ser interpretados como una alegoría política, pero también tienen una lectura intimista [...] son historias sin tabúes ni prejuicios [...] Muchas de mis temáticas pueden pensarse adultas: la nostalgia, la crítica social, el mismo marco social en el que pongo a vivir a mis personajes. Son guiños adultos, porque son ellos los que compran los libros y porque yo también soy adulto (Buitrago en Marín, 2012, párr. 7).

Las obras de Francisco Montaña Ibáñez, por su parte, también mantienen una relación con la realidad política y social del país, que se expresa de forma mucho más directa en su escritura. Los contextos en los que se mueven sus personajes o bien están permeados por la atmósfera de la militancia y de la violencia política, o bien por condiciones de violencia estructural, como la pobreza, el hambre, el maltrato y el abandono; en ambos escenarios se ponen en tensión los lugares comunes acerca de los niños, por cuanto estos, a su vez, se ubican en situaciones complejas y de extrema violencia que les demandan su reconfiguración constante; además, se pone de presente el lugar de la socialización política en la configuración de la subjetividad y de los legados generacionales.

A la manera de quienes Logie y Williem (2015) denominan "una nueva generación de narradores", Montaña Ibáñez, nieto del último presidente del partido político Unión Patriótica (UP), Diego Montaña Cuéllar, 
se posiciona con su escritura respecto de la "derrota política que sufrió la generación anterior" (p. 2). Para este autor, su propósito con la literatura y los temas que trata guardan estrecha relación con su experiencia de infancia, cercana a la militancia de izquierda; así lo refiere cuando intenta situar la emergencia de su libro El gato y la madeja perdida:

Es difícil encontrar el principio de esta historia, por eso el libro se llama la madeja perdida, porque el principio de esta historia para mí se diluye un poco en mis recuerdos de infancia más lejanos. Primero, mi abuelo fue el último presidente de la Unión Patriótica; antes de eso, uno de mis primeros recuerdos de infancia es estar de la mano [...] viendo a mi mamá haciendo trabajo político en los barrios de Bogotá, de manera que para mí el asunto de la militancia política siempre fue una cosa que estuvo muy cerca de mi infancia, y entonces eso determinó, evidentemente, mi manera de pensar y de ver el mundo y de entender la literatura y de entender lo que yo quiero hacer con la literatura (Montaña, en Reyes, 2016).

El gato y la madeja perdida es producto de una investigación del genocidio del partido, financiada por la Universidad Nacional de Colombia, donde Montaña Ibáñez es profesor. Parte del trabajo propuesto durante la investigación tuvo que ver con la realización de entrevistas a personas que fueron niños y jóvenes durante el periodo del exterminio de la up, de manera que experimentaron, muy de cerca, la militancia política de sus familiares. Dicha militancia en la izquierda les atribuyó ciertas características a los entornos de socialización que acompañaron la infancia y la juventud de la generación de hijos y nietos, algunas de las cuales están presentes en la narrativa de Ana María, el personaje narrador y protagonista de la novela.

En las entrevistas llevadas a cabo, Montaña y su equipo de investigación les preguntaron a hijos y nietos de militantes de la up ¿cómo fue su infancia?, y en sus respuestas siempre afloró la rememoración del familiar cercano asesinado. Montaña cuenta que la escritura de este libro tuvo que ver con una deuda histórica con el pasado de la organización y con el encuentro con las organizaciones de hijos en Colombia. De hecho, en los agradecimientos del libro, menciona a personajes como, Bernardo Jaramillo Zapata, José Antequera Guzmán, María José Pizarro e Iván Cepeda, entre otros, todos ellos hijos de figuras de la vida política asesinados entre finales de la década de los ochenta y principios de los noventa. Acerca de este encuentro con las organizaciones de hijos como temple de ánimo para la escritura de su libro (y de otros dos que se encuentra elaborando), Montaña señala:

[...] y empezaron estos muchachos [hijos y nietos colombianos] a reclamar un espacio político, histórico de reconocimiento en la sociedad 
colombiana, en la forma de ver la historia de nuestro país que me pareció de un valor y de una integridad y de una dignidad enorme. $Y$ entonces yo sentí una resonancia inmediata con esas personas que estaban reclamando y construyendo y dándose a sí mismos ese lugar. Y dije, tengo que escribir algo sobre esto, no tuve la menor duda acerca de eso. Entonces comencé a buscarlos, a los hijos, a los hijos de los desaparecidos, de los muertos (acabaron con el partido político, es una cosa infame lo que pasó), y empecé a hacer entrevistas (Montaña en Reyes, 2016).

Para Montaña, El gato y la madeja perdida es "un homenaje a la memoria. A los muchos sentidos que esa palabra puede tener para los seres humanos, a lo difícil que es recordar cuando se trata de hechos colectivos y traumáticos" (Montaña, 2013, p. 149). Además de la reivindicación del carácter colectivo del drama de su generación, Montaña reclama el lugar de su escritura en el aporte a "construir una sensibilidad frente a la historia de nuestro país que incluya las voces de los que siguen siendo nombrados como vencidos o víctimas" (p. 149), y valora el aporte de las distintas personas que trabajan por "conseguir la justicia y porque lo que sea que esa enorme palabra pueda contener nos incluya a todos" (p. 150). En estos enunciados se pone de presente el posicionamiento del autor en torno al pasado — del cual se sabe partícipe-, al tiempo que sitúa unos imperativos éticos en relación con ese pretérito, planteando formas de traerlo al presente.

Francisco Montaña también dirige su escritura a otras problemáticas de orden social. En el conversatorio titulado Colombia siente ${ }^{5}$ (2018), que reunió a los escritores Pilar Lozano, Gerardo Meneses y Francisco Montaña, Silvia Castrillón preguntó a los panelistas por la presencia de algún tipo de compromiso en su escritura; a esto, Montaña contestó haciendo referencia a su experiencia de infancia en medio de la militancia política de su familia y a la influencia que esta tuvo en su lectura de mundo marcada por el marxismo, cuestión que le lleva a asumir una postura política en su escritura, según la cual varias de las problemáticas sociales son producidas por "la enfermedad del capitalismo", lo que permea su obra (Montaña en Castrillón, 2018). Montaña puntualiza su compromiso en la mirada sobre las relaciones de poder desarrolladas en sus obras, así como sobre el lector que se figura en estas:

[...] desde que empecé a escribir he visto cómo es muy difícil para mí impedir que lo que yo veo de la realidad [...] pase a la escritura en un personaje, en un gesto, en un tipo de relación de poder, porque esto modela relaciones de poder, este tipo de cultura nuestra modela relaciones de poder donde [...] la víctima se vuelve victimario

5 Realizado el jueves 19 de abril de 2018 en la Feria Internacional del Libro de Bogotá. 
inmediatamente tiene la mínima posibilidad. Entonces creo que es por ahí como he asumido mi compromiso y me parece que claramente escribo para los niños colombianos, yo escribo para los lectores colombianos (Montaña en Castrillón, 2018).

Con todo, es posible ver cómo la mirada que los autores plantean respecto de la realidad política del país se torna imposible de situar estrictamente en el pasado por cuanto los fenómenos sociales que señalan se siguen repitiendo, aún después de la firma de los acuerdos de paz entre el Gobierno nacional y la otrora guerrilla de las FARC-EP, ${ }^{6}$ hoy partido político. Con sus obras, estos tres autores participan del presente y de los horizontes de futuro, no solo porque la temporalidad compleja de la memoria y el emprendimiento de trabajos a su alrededor impliquen revisitar el pasado para reconstruir sus sentidos en el presente, sino porque sus voces son, al mismo tiempo, memoria del pasado revisitado, crítica al panorama actual y espacio político potencial para la transformación de la cultura y para la figuración de otras posibilidades de ser y estar en el mundo.

Respecto de la continuidad y las distintas formas de existencia del pasado en el presente Francisco Montaña señalaba a inicios del año 2016 que, aun en ese momento, el exterminio por razones políticas, como el que se perpetró en contra de la up, continuaba ocurriendo; se refirió al caso del movimiento político Marcha Patriótica, que hasta noviembre de 2017 había reportado el asesinato de 140 de sus líderes (Montaña en Reyes, 2016; "'La paz nos está costando la vida': Marcha Patriótica" ). Respecto de esta situación, la Defensoría del Pueblo reportó 311 asesinatos de líderes sociales y defensores de derechos humanos entre el 1. ${ }^{\circ}$ de enero de 2016 y el 30 de junio de 2018; los picos experimentados en algunos momentos, incluido el posterior a las elecciones presidenciales del 17 de junio, se atribuyen a diversas razones: la defensa de territorios, la implementación de los acuerdos de paz en lo referente a la reclamación de restitución de tierras y a la sustitución de cultivos ilícitos y la opción política alternativa de líderes durante la campaña presidencial ("Asesinatos de líderes sociales: una crisis humanitaria").

Si bien las idas hacia el pasado explícitas que plantean Jairo Buitrago y Francisco Montaña sitúan referencias en acontecimientos puntuales del pasado, en estos se ubican fenómenos que se repiten en el presente del país, lo que les provee de una temporalidad que se pasea entre el pasado y el presente. Lo mismo ocurre con las obras de Triunfo Arciniegas, pero la razón en este caso tiene que ver con la ausencia de la mención explícita a un acontecimiento específico.

6 Después de la firma de los acuerdos de paz, en noviembre de 2016, las Fuerzas Armadas Revolucionarias de Colombia-Ejército del Pueblo se convirtieron en el partido político Fuerza Alternativa Revolucionaria del Común. 
Aunque los acercamientos a los acontecimientos del pasado son diferenciados en los tres escritores, todos logran trascender las fronteras de la realidad del país y encontrar la identificación de los lectores de otras latitudes con las realidades que relatan. Las historias de Triunfo Arciniegas, con la ausencia de menciones explícitas logran construir símbolos que se pueden leer como propios en cualquier lugar del mundo. Sucede de forma similar con varias de las obras de Jairo Buitrago, las cuales logran identificar problemáticas situadas, que pueden considerarse como parte de la realidad latinoamericana. Incluso Francisco Montaña, quien trabaja de manera más puntual el genocidio de la Unión Patriótica y declara su intención de escribir para lectores colombianos, ubica otros referentes latinoamericanos, particularmente Argentina, en relación con los trabajos de memoria emprendidos con las organizaciones de hijos, con quienes se reconocen experiencias compartidas como producto de la violencia política de los setenta y los ochenta y de las apuestas sobre el orden social que compartían las organizaciones de izquierda.

En las obras de los tres escritores, explícita o implícitamente, se encuentra la figura de la herencia de la generación anterior como hacedora de los pasados a los cuales se refieren, una relación en la que la generación más joven recibe su legado de la anterior, pero lo hace seleccionándolo y reinterpretándolo. En palabras de Logie y Williem (2015) estos escritores

[...] desarticulan las formas unívocas del pasado escribiendo desde otra temporalidad, la del presente, al tiempo que formulan una respuesta matizada a la herencia de los 70, una respuesta que supone la construcción de nuevos sentidos, pero también el rechazo de otros (p. 2).

En este sentido, las obras literarias actúan, además, como artefactos culturales capaces de generar cambios en la cultura, en arreglo a las modificaciones en las representaciones del pasado y del presente. Al respecto, Krips (2000) señala que los libros infantiles calibran cambios culturales que llegan a ser considerados en términos de herencia en la medida en que la infancia (pasado) se rememora en la escritura del adulto (presente), por lo cual en las apuestas éticas y políticas de los autores se encontraría implícita una transformación de la cultura con base en la reinterpretación del pasado:

Los libros son capaces de esta hazaña como resultado de la relación de adulto a niño que se encuentra en el corazón del género. Las novelas infantiles representan invariablemente al presente (el niño) desde la perspectiva del pasado (casi invariablemente son escritas por los adultos): cuando estas toman el pasado como tema, son más agudamente receptivas a cambios sutiles en las representaciones culturales del pasado y del presente (p. xii). 
En el caso de Montaña y Buitrago, acaso por ser parte de esa "generación 1.5" en la que se encuentran "aquellos que vivieron de niños los hechos traumáticos en carne propia, aunque sin comprender, debido a la edad que tenían, el alcance verdadero de los acontecimientos, que sin embargo atraviesan la memoria almacenada en sus propios cuerpos" (Logie y Williem, 2015, p. 4) —con respecto a la violencia de los setenta y los ochenta-, acaso por la matriz discursiva en la que se encuentran escritas sus obras (la novela realista y el libro álbum con referencias explícitas a hechos puntuales, a manera de "guiños adultos"), resulta más evidente la idea de la deuda que el hijo contrae con sus antecesores y que, al mismo tiempo, reclama "la legitimidad de su propio lugar de enunciación" (p. 2), a lo cual habría que agregar la idea de compromiso con las nuevas generaciones. En los dos autores esto se expresa en relatos narrados en primera persona que permiten "dar cuenta de la imposibilidad de la representación objetiva del pasado mediante un énfasis en su propio carácter construido" (p. 9). En Buitrago se enuncia a manera de trasfondos históricos situados (que logran un alcance amplio en la identificación de los lectores de otras latitudes), mientras que en Montaña adquieren forma tanto en el proyecto mismo que acompaña la escritura, como en sus personajes y en la versión que cuentan del pasado. A continuación, se presenta un análisis de las formas de narrar la violencia política en las obras de los tres escritores, particularmente de los modos de enunciar las fuentes de la violencia.

\section{Formas de narrar la violencia política}

Como se señaló en el primer apartado, en el entre generacional se ponen en juego sentidos del pasado que las generaciones adultas transmiten a las más jóvenes. En esta idea de la transmisión opera la forma narrativa, de manera particular la ficción literaria como posibilidad de comprender y de hacer comunicable el pasado reciente (Nofal, citada por García, 2016). En esta vía, vale la pena preguntar ¿cómo se narra la violencia política en la literatura infantil colombiana? ¿De qué manera el fantasy literario — para acuñar la categoría propuesta por Nofal— representa las experiencias de desaparición, de exilio, de genocidio, entre otros fenómenos y acontecimientos que configuran la historia reciente del país? Para continuar con el análisis en torno a estas preguntas se retomarán las obras El árbol triste (2005; 2009) y El último viaje de Lupita López (2011), de Triunfo Arciniegas; Camino a casa (2008) y Eloísa y los Bichos (2009), de Jairo Buitrago; y No comas renacuajos (2008) y El gato y la madeja perdida (2013), de Francisco Montaña. Se discutirán, en primer lugar, las matrices discursivas y el tipo de narrativa construidas por los escritores; en segundo lugar, las formas de enunciar las fuentes de la violencia; $y$, en tercer lugar, algunos elementos comunes en las seis obras. En primera 
instancia, en lo que respecta a las matrices discursivas y el tipo de narrativa construidas por los escritores se hará, a continuación, una breve reseña de las seis obras.

El árbol triste y El último viaje de Lupita López del escritor Triunfo Arciniegas son álbumes ilustrados, ${ }^{7}$ el primero por Diego Álvare $z^{8}$ y el segundo, por Henry González. ${ }^{9}$ El árbol triste relata una historia sobre la guerra y el exilio, construida desde la voz narrativa de una niña que ve llegar tres pájaros al árbol que está frente a su ventana. Después de observarlos y estudiarlos junto con su padre, la niña descubre que el país del cual provienen se encuentra en guerra y que los viajes de ida y regreso de los pájaros se vuelven irregulares porque se debaten entre permanecer en su país o regresar al árbol y mantenerse lejos de la guerra; ellos llegan cada vez más maltrechos, más tristes, más ansiosos.

El último viaje de Lupita López cuenta la historia de Lupita, una anciana, y su pequeño pez, Vicente. Además de la vejez y la muerte, el diálogo entre texto e imágenes produce referencias al malestar de la idea del desplazamiento del campo a la ciudad, al dolor, el desasosiego y la incertidumbre que produce la desaparición de alguien querido: un día Vicente, el pececito, se esfuma por el sanitario por causa de un desafortunado incidente. El desgarramiento de la anciana mujer ante la ausencia de su pececito es ilustrado con maestría por Henry González: Lupita parece haberse perdido, junto con Vicente, en "las profundidades sin nombre" (Arciniegas, 2011, p. 30); se halla a sí misma ahogada en el mar de su angustia, con el corazón necesitado de abrigo; hasta su propia casa se convierte en amenaza, volcándose sobre ella como un gran monstruo de dientes afilados; doña Lupe, "casi un fantasma". Solo la ayuda de Ramón, el plomero, quien tiene la clara instrucción de encontrar a Vicente, aunque deba desbaratar la casa, logra devolverle a Lupita el sosiego y la tranquilidad, para que

7 De acuerdo con Rosero (2010), el libro álbum ilustrado es "un tipo de libro donde la imagen y el texto adquieren un nivel de significación que se activa con la relación de ambos lenguajes. Generalmente es un libro en tapa dura, de unas cuarenta páginas, donde la ilustración ocupa el total de la hoja y los textos son simplificados a un par de frases por cada doble página" (p. 5). Las relaciones entre la ilustración y el texto pueden tener diversos matices: de acuerdo con la tipología presentada por Rosero, en el caso puntual de las obras de Triunfo Arciniegas las ilustraciones tienen una relación de clarificación, el texto existe previamente y la imagen recrea y resignifica hechos de la narración; en el caso de las obras de Jairo Buitrago y Rafael Yockteng la relación entre el lenguaje visual y el lenguaje escrito es simbiótica, es decir, son mutuamente dependientes, si se sustrae o bien el texto, o bien la ilustración, la narración "se derrumba" (2010, p. 12).

8 Diego Álvarez es oriundo de Buenos Aires, Argentina. Estudió Diseño Gráfico en la Escuela Nacional de Artes Plásticas de la UnAm y ha trabajado como diseñador e ilustrador. Actualmente vive en México.

9 Henry González nació en Bogotá, Colombia. Ha participado como ilustrador en numerosos proyectos de literatura infantil y juvenil con reconocidas editoriales. Actualmente reside en Medellín y trabaja en El lápiz Azul Taller y Oficios del cual es cofundador. 
pueda partir a un viaje sin retorno, el más largo de su vida, en compañía de Vicente, el desaparecido que regresa "un poco flaco y algo maloliente, con una aleta quebrada" (p. 46).

Jairo Buitrago comparte la autoría de los álbumes Camino a casa y Eloísa y los bichos con Rafael Yockteng, ${ }^{10}$ quien los ilustra. En el primero, los autores presentan a una niña que recorre escenarios de su cotidianidad acompañada por un león, el cual, en un evento fantástico que desencadena el relato, cobra vida y desciende de un monumento que, vale la pena señalar, tiene una placa conmemorativa en la que se lee "1948", año en que fue asesinado Jorge Eliécer Gaitán y representa un hito importante del pasado del país en el que algunos sitúan el inicio del periodo conocido como La Violencia. ${ }^{11}$ En las últimas páginas de este libro aparece el retrato de un hombre con una melena de león sobre la mesa de noche y, junto a esta, una pila de periódicos en los que se lee la frase "familiares de desaparecidos 1985", una fecha que también resulta significativa en el pasado reciente del país. ${ }^{12}$ Esta fotografía permite establecer el enlace entre la figura del león y la del padre ausente; dicho de otro modo, el personaje fantástico se presenta como la metáfora desde la cual la niña recupera al ausente y lo trae de nuevo a la cotidianidad. Ambos personajes, león y padre — quienes pudieran leerse como unidad - únicamente existen de manera explícita en el juego de diferenciación/unificación, en la ilustración.

En Eloísa y los bichos, de los mismos autores, también una niña se encuentra ante una situación que altera su entorno. Esta vez se trata de la migración que afrontan Eloísa y su padre. En un lugar que le es completamente extraño, la niña ve a los demás como todo tipo de insectos gigantes. El texto permite acercarse al sentimiento de extranjeridad al cual se refiere Eloísa desde el inicio del relato — "Yo no soy de aquí"—, y a las formas como percibe el mundo que le es ajeno, que no están únicamente vinculadas con las representaciones de los otros, sino también con el lento transcurrir del tiempo y con la proporción de los espacios que es

10 Rafael Yockteng nació en Lima, Perú, en 1976, pero reside en Colombia desde 1980. Adelantó estudios de Diseño Gráfico en la Universidad Jorge Tadeo Lozano en Bogotá, Colombia. Yockteng y Buitrago han realizado numerosos proyectos juntos.

11 Hablar de La Violencia (con mayúscula) en la historia reciente del país tiene una connotación diferenciada de la violencia como fenómeno político y social generalizado. La Violencia hace referencia al periodo comprendido entre 1948 y 1953 (inicio de la dictadura de Rojas Pinilla), para algunos, y, para otros, entre 1948 y 1958 (con el inicio del Frente Nacional).

12 El 6 y 7 de noviembre de 1985 un comando guerrillero del M-19 se tomó el Palacio de Justicia en Bogotá. Las Fuerzas Armadas respondieron de manera violenta y sin ningún tipo de cuidado por la vida de las personas que se encontraban en medio del fuego cruzado (miembros de la Corte Suprema de Justicia, trabajadores y visitantes ocasionales de Palacio). El saldo de este evento fue una edificación en llamas que debió ser reconstruida en los años siguientes, más de un centenar de muertos y doce desaparecidos, entre ellos, una guerrillera (Irma Franco), visitantes ocasionales y trabajadores y proveedores de la cafetería del Palacio.

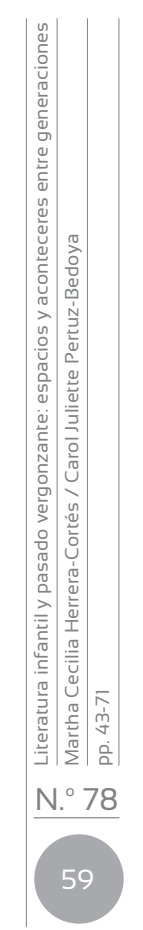


recreada en la ilustración: en un principio los espacios son grandes y Eloísa se siente infinitamente pequeña en ellos; cuando la interacción con los otros se va haciendo más fácil, los espacios se hacen más amigables y el tiempo pasa más rápido. En este álbum, es una Eloísa adulta quien narra la historia de su llegada y su proceso de adaptación a una ciudad distinta (narradora retrospectiva o extradiegética en la terminología de Genette) y la cuenta a un oyente implícito que bien puede ser interno, pues el libro cierra con una ilustración en la que aparece la maestra Eloísa rodeada por sus estudiantes, entre quienes se ve un "bichito raro". La historia muestra la reconfiguración de la cotidianidad y lo que representa para el sujeto "hacerse un lugar" en un sitio extraño para que ya no lo resulte tanto. En su relato, Eloísa hace referencia a la forma como todo se va haciendo mejor sin que por ello sea posible olvidar "lo que se deja atrás" — su madreni dejar de sentir tristeza. Al igual que en Camino a casa, el ausente se ilustra, pero no se nombra de manera explícita.

En las dos historias de Buitrago y Yockteng la situación que altera el entorno de las protagonistas no es el material del texto sino las formas como este entorno se ve afectado y las maneras como se reconfigura. En ninguno de los dos textos se nombra explícitamente la problemática de violencia política ni sus causas, ni las fuentes del hecho violento que generó una ruptura en la cotidianidad. Ambos muestran una infancia descolocada que se reinventa y encuentra maneras de estar ante nuevas circunstancias.

En los libros de Buitrago y Arciniegas hay múltiples posibilidades de lectura (al estilo de capas o niveles) que dependen de los marcos de comprensión que el lector haya logrado construir y que se ven alimentados por el diálogo entre el texto y la imagen.

En No comas renacuajos Francisco Montaña cuenta la desgarradora historia de una familia conformada por cinco hermanos golpeados por el abandono, el hambre y la pobreza. Los mayores, María y Héctor, de doce y trece años respectivamente, asumen el rol de adultos ante la muerte de su madre y la partida de su padre a un pueblo de Colombia. David, de nueve años, el único sobreviviente de los hermanos, está en un hogar de paso para niños que se encuentran temporal o permanentemente sin ningún adulto que se haga responsable de su cuidado. Allí conoce a Nina, una niña cuyos padres son presos políticos y se encuentra a la espera de que su madre sea liberada para irse, junto con ella, al exilio. Esta novela realista es narrada a dos voces: un narrador omnisciente que describe la situación de los hermanos y se sitúa en el pasado del tiempo cronológico de la obra, y una narradora protagonista que es en este caso una niña que intenta hacerse amiga de David, el niño inmortal a quien las balas no le hacen daño, que defiende a sus compañeros de los tratos injustos, pero no habla con nadie, y apunta y dispara a todos con un arma imaginaria formada con sus manos. 
Por su parte, El gato y la madeja perdida, del mismo autor, es una novela que muestra el tránsito de una niña hacia su juventud en medio de un torbellino de situaciones que le llegan "como un roquetazo": el asesinato de su abuelo (militante de la up), el divorcio de sus padres y la noticia de que su profesor está enamorado de ella. A través de la voz de Ana María se narra la historia desde el momento en que recibe la noticia del asesinato de su abuelo hasta cuando la madeja de las verdades acerca de este evento puede empezar a desenredarse después de unos días complejos en los que el tiempo transcurre diferente y la fantasía y la realidad se mezclan sin que sea fácil diferenciarlas.

Las obras de Arciniegas y Buitrago responden al género del libro álbum, en tanto que las de Francisco Montaña se inscriben en el género de la novela realista. En los álbumes la fantasía y la realidad conviven sin mayores tensiones, mientras que en las novelas de Montaña la fantasía del mundo infantil de Ana María choca con el mundo adulto que ya no la reconoce como niña y la insta a desplazarse al lugar de adulta. En los tres autores, aunque en diferentes proporciones y con mayor o menor centralidad por el tipo de matrices discursivas en los que se inscriben, el lenguaje alegórico y las metáforas tienen un lugar relevante.

En segunda instancia, en lo que respecta a las formas de enunciar las fuentes de la violencia (socio)política, esta se ha adjudicado en muchas ocasiones a una suerte de mano invisible. Este es, tal vez, uno de los puntos de encuentro de las obras de Arciniegas, Buitrago y Montaña, aunque los tres lo hacen con características diferenciadas, como se intentará mostrar a continuación. Si bien las obras reseñadas se ubican en lo que García denomina "una zona intersticial entre la memoria y la imaginación", narran la violencia desde diferentes protocolos ficcionales. Arciniegas y Buitrago, optan por no hacer una mención explícita de las fuentes de la violencia; ubican, sin que sea el centro de su relato, hechos victimizantes, pero no otorgan identidad a quienes perpetran tales hechos (sujetos, instituciones, organizaciones).

Arciniegas (2009) crea unos hombres absurdos, que se disputan el aire, desfigurados, casi monstruosos, "de ojos diminutos y dedos como raíces. El agujero de la boca abarcaba casi toda la cara" (p. 46). Y entonces la guerra se entiende como un artificio de los hombres, como un problema humano, irracional que, a su vez, desfigura al humano. Por otro lado, para doña Lupe y Vicente, la fuente de la amenaza, que es también desfigurada hasta la monstruosidad, proviene del lugar que solía proteger y resguardar: la casa.

Buitrago, por su parte, sitúa en Camino a casa (al menos en una de sus capas de lectura) un referente amplio enmarcado en dos periodos como fuente de la violencia producto de la cual ha desaparecido el padre: el de la época de la Violencia, con el detonante del asesinato de Gaitán, y el de la 
violencia de mediados de la década de los ochenta que constituye un panorama complejo en el que se entrecruzan las guerrillas, el paramilitarismo, el narcotráfico y el terrorismo de Estado; es decir, la fuente de la violencia se ubica en el contexto sociopolítico nacional.

En contraste con las dos formas anteriores de configurar las fuentes de la violencia, Francisco Montaña, en su obra acerca de la Unión Patriótica, da algunas puntadas acerca de quienes estarían involucrados en el asesinato de los militantes del partido. Así, se refiere a las figuras de unos hombres vigilantes cuya sola presencia es ya símbolo de amenaza sobre la vida:

Mi papá se asomó a la ventana, yo lo seguí. En el jardín, viendo esa misma luna minúscula sobre el azul petrolizado del cielo, dos hombres extraños. Parecían gemelos. Estaban vestidos de manera idéntica. En sus muñecas relumbraban sendas cadenas de oro. Nos miraron desafiantes. Vi a mi papá mirarlos con tranquilidad. Yo tuve miedo (Montaña, 2013, p. 145).

Al mismo tiempo, este escritor sitúa ambigüedades en las impresiones de su personaje en relación con las Fuerzas Armadas. En un momento confuso que parece estar ubicado entre el sueño y la vigilia, en los días posteriores a la muerte de su abuelo, Ana María recrea una escena en la que "miles de policías armados" disparan hacia el edificio en el que se encuentra su padre, le disparan a él; mientras ella lo observa y piensa en pedirle que se proteja, un soldado que parece inconforme con lo que está sucediendo llega a su lado y les pide a ella y a otros niños que se lancen al suelo para protegerse; después los saca del edificio, los lleva a un lugar seguro y les pide que no digan nada de lo que ocurrió. Luego estas fuerzas amenazan, pero también protegen; se muestran inconformes con las actuaciones de otros en su mismo bando, pero al mismo tiempo piden silencio.

No obstante, si bien por momentos es posible leer una relación ambigua con las Fuerzas Armadas, Montaña no titubea en condenar —a través de la voz de Ana María - al Estado por la represión de las décadas de los setenta y los ochenta, por su alianza con múltiples sectores para adelantar la aniquilación de la oposición política y por su negligencia para atender con medidas de protección solicitadas y con la justicia demandada:

Un plan forjado por la inteligencia del Ejército y el Estado Ilamado el Baile Rojo que contó con los ejércitos ilegales de los narcotraficantes inició el genocidio que se consolidó con el "Plan Golpe de Gracia" mediante el cual se pretendía acabar físicamente con todos los militantes y simpatizantes de la up en el país (p. 70). 
En No comas renacuajos, Montaña presenta, si se permite la diferenciación, la crisis social y la crisis política expresadas en dos de sus personajes. No hay mención de la fuente de violencia en la arista política. Solo se sabe que el padre de Nina es un preso político recluido en una cárcel de la costa y que su madre lleva seis meses presa "por lo mismo". Pero ¿qué significa ser un preso político?, ¿qué representa hablar de presos políticos en Colombia cuando (en el plano de la realidad del escritor) durante cierto periodo (que coincide con la publicación de la primera y la segunda edición del libro) no se reconocía siquiera la existencia de un conflicto interno y algunas figuras de la vida política habían dicho en repetidas ocasiones que "en Colombia no hay presos políticos"? La definición breve de la Convención Europea de Derechos Humanos plantea que "un preso político es una persona que a causa de sus creencias y actividades políticas está encarcelada" (Strasser, 2013, párr. 3); con las respectivas salvedades, un preso político ve afectadas las garantías mínimas de su ejercicio político y esto tendría que ver, fundamentalmente, con "razones políticas del gobierno" (párr. 4); en este sentido, es allí, en la institucionalidad del Estado, donde se ubicaría la fuente de la violencia en este libro; un Estado dispuesto a defender a través de cualquier medio su apuesta para el orden social.

Tenemos, entonces, que la enunciación de las fuentes de la violencia en estos tres autores transita por el señalamiento de un problema de la irracionalidad humana (aparentemente masculina), presente en Arciniegas; el marco histórico sociopolítico del contexto nacional, situado por Buitrago; y la responsabilidad del Estado, señalada por Montaña.

En tercera instancia, como una posibilidad de continuar observando las formas de narrar la violencia política, se estima pertinente discurrir en torno a un escenario recurrente que permite otorgar ciertas características a las obras analizadas: la casa. Se trata de un escenario que puede encontrar la razón de su coincidencia con la característica intimista de las narrativas de los tres escritores, a partir de la concentración en aspectos de la cotidianidad del ámbito familiar y doméstico.

En las obras de Arciniegas la casa se constituye en un lugar ambivalente. En El árbol triste (2009), es el lugar en el que se anhela estar, pero que al mismo tiempo representa una amenaza para la vida, por eso en varias ocasiones los pájaros intentan, sin lograrlo, instalar su hogar en otro lugar: un árbol ubicado en el jardín de una casa de otro país. Están en este nuevo lugar "hasta volverse parte del paisaje" (p. 20), y entonces es el nuevo hogar el que sufre de tristeza por la partida de los pájaros: "El árbol ya no era el mismo. Sin el temblor de las plumas, sin la tibieza de los cuerpos, había quedado triste. Sus hojas caían como lágrimas" (p. 22). 
En El último viaje de Lupita López (2011), con el aporte de la ilustración de Henry González, la casa pasa de ser el lugar acogedor que no se abandonaría ni se cambiaría por "ciudades ruidosas y agitadas, donde todos pasan de prisa, sin saludar a nadie, y se estiran como gatos hasta los huecos de las ventanas a imaginar el paisaje" (p. 4), a convertirse en un lugar frío, en un mar vertiginoso de "profundidades sin nombre" (p. 32), monstruoso, de ojos luminosos y dientes afilados en una boca enorme, capaz de devorar a Vicente, el pececito.

En Camino a casa, Jairo Buitrago muestra este escenario como el lugar donde transcurre una cotidianidad alterada por la ausencia del padre: una niña, apoyada en una escalera improvisada con ladrillos apilados, prepara la cena para su hermano pequeño y para la madre, que más tarde regresa agotada de la fábrica. El espacio tiene rasgos que denotan la condición de pobreza de la familia, por su ubicación — que evoca la periferia de las grandes ciudades-y por algunas características como los muebles desvencijados, las paredes resquebrajadas y la manta remendada. La casa es el lugar de la ausencia y, a la vez, el espacio donde se espera al otro, donde se anhela su presencia, donde se acumula su memoria.

Entre tanto en Eloísa y los bichos la casa es el lugar que se deja atrás y se debe construir en una ciudad distinta, aunque su construcción no depende exclusivamente del espacio físico, sino de la posibilidad de hacerse a un lugar, de crear vínculos con otros y de aprender a desenvolverse en las calles; en últimas, de aprender a vivir, como lo relata Eloísa. Así, la casa, más que un espacio cerrado, tiene una connotación más amplia que abarca la ciudad y en ella la escuela, el mercado, el transporte, así como el padre — quien junto con el recuerdo de su madre son lo que se preserva del hogar anterior-, los amigos y, más adelante, una profesión y una familia propia.

En El gato y la madeja perdida, la casa es para Ana María, después de la muerte de su abuelo, el lugar de las ausencias: no solo la de su abuelo asesinado, sino la de su padre, separado del hogar; la de su madre, sumida en la depresión; la de su hermano, absorto en sus propias preocupaciones. Asimismo, es la zona conminada que puede representar riesgo para la vida de todos, no solo para los adultos militantes. Como se indicó, en los sueños de Ana María su padre es atacado en el edificio donde vive; en una de las últimas escenas construidas por el escritor, ella observa con miedo a los hombres que vigilan el apartamento de su abuelo donde ahora está instalado su padre.

La casa representa para Nina y David, los dos personajes focalizados en No comas renacuajos, cuestiones diferentes, aunque para ambos se deshace hasta llevarlos a la institución en la que sus historias se entrecruzan. Para David, en su casa ocurre una cotidianidad que es también alterada, como en el caso de Camino a casa; no obstante, en esta historia 
la ausencia es de ambos padres. En este escenario transcurren los días de hambre, enfermedad y muerte de cinco hermanos que intentan sobrevivir al abandono y a la pobreza con dos hermanos mayores de doce y trece años que intentan asumir el rol de adultos. En el caso de Nina, la cotidianidad del hogar no aparece narrada, pero igual que para Ana María, la casa debía representar una amenaza porque ella y su madre se irían del país una vez su madre fuera liberada de la cárcel.

Con todo, en las narrativas de estos escritores la casa se constituye en pretexto para mostrar el universo íntimo y subjetivo que permite dar cuenta de las formas como la violencia política penetra en todos los ámbitos de la vida e impone condiciones que demandan de parte de los sujetos su reconfiguración. La casa representa, así, las ambigüedades de un espacio que puede ser de resguardo y de amenaza, de encuentro con el otro y de soledad y vacío. Estas "narrativas del yo", intimistas y subjetivas, permiten observar también que para los personajes de las obras analizadas la imaginación se presenta como posibilidad para habitar el mundo, para reconfigurar sus subjetividades en el marco de acontecimientos de violencia política que irrumpen en la vida cotidiana, para completar los vacíos de la memoria y las ausencias de sentido. De acuerdo con Logie y Williem (2015), "la insistencia en el ámbito doméstico no debe leerse, sin embargo, como un gesto apolítico, porque constituye asimismo un comentario crítico al fenómeno de contaminación del territorio privado" (p. 4). Al fin y al cabo los seres humanos nos configuramos y constituimos en torno a un tiempo vivido en el que se entrecruza lo cotidiano con otras esferas sociales y es lo que nos hace sujetos a la luz de un contexto histórico que permea tanto lo individual como lo social.

\section{Potencialidades de literatura infantil para el trabajo de memoria en clave intergeneracional}

Las miradas sobre los autores, sus relaciones con el pasado y su cita con el presente son, al mismo tiempo, miradas que se detienen en las nuevas generaciones. La clave generacional constituye, entonces, un entrecruzamiento temporal en el que se encuentran expresiones del orden ético-político que demandan situar la responsabilidad de los adultos con las generaciones más jóvenes respecto de la apropiación de la historia en la que aterrizan para vivirla, pensarla y crear con ella algo nuevo (Meirieu, 1998), pues, en términos de Redondo (2012),

[...] la infancia devendrá infancia, solo en la medida en que su presencia se anude en una serie histórica más larga, en un "entre", en un relato de tiempo que inscriba la experiencia infantil en dicha sucesión, en un entrelazamiento temporal espacial inter/entre generacional. La infancia 
representa un tiempo de espera como también un tiempo de posibilidad para que acontezca aquello que no ha sido nombrado y conocido aún. La infancia es y será el enigma, continuidad y discontinuidad de la humanidad, si hay adultos que respondan a la llamada (p. 106).

Solo en esta inmersión temporal es posible que las generaciones más jóvenes encuentren la oportunidad de la interrupción, entendida como una "alteración radical de lo que acontece". En los niños, las niñas y los jóvenes se instauran la "posibilidad y [la] potencialidad de desdecir los fatalismos apocalípticos, así como los discursos solo auto-referenciados en puro presente inmediato muy ligados al consumo" (Redondo, 2012, pp. 111112). Pero ello solo es posible en la medida en que, como menciona Redondo, los adultos respondamos a la llamada.

Vale la pena señalar que "reconocernos y reconocer al otro, desde una perspectiva intergeneracional" (Herrera y Pertuz, 2016, p. 243) como parte del compromiso de asumir trabajos de memoria en torno al pasado reciente, "requiere de un 'entre' generacional generoso, sesgado por la hospitalidad" (Redondo, 2012, p. 107). En este ejercicio la literatura infantil ofrece la posibilidad de construir puentes en los que es posible cruzar en las dos direcciones (Machado, 2018). Con todo,

Pensar en los niños nos ubica ante la necesidad de reflexionar sobre nuestras herencias, no como un ejercicio retórico cargado de buenas intenciones sino como un accionar activo en este presente histórico que ofrece a la sociedad [...] una nueva oportunidad de curvar la vara hacia la igualdad [...] es deseable imaginar que el despertar en los niños la palabra represente una posición asumida "entre" generaciones y que las diferencias no sean brechas de profunda desigualdad sino la diversidad de modos de estar en un mundo abierto a las posibilidades de otros mundos (Redondo, 2012, pp. 111-113).

Las obras referenciadas comparten la posibilidad que les dan a sus personajes (y al lector) de pensar, de completar vacíos, de hacer preguntas, porque en ellas no todo está dicho y se ubican lejos de la intención moralizante o protectora de la infancia. Tampoco enarbolan banderas de proyectos políticos para el adoctrinamiento en su favor. Se dedican, por el contrario, a pensar en lo que la guerra no da tiempo de pensar: en los sujetos y en sus distintas estrategias para reconfigurarse; en los residuos de la violencia política, en las maneras de afrontar las situaciones y de encontrar sosiego y esperanza, pero también en el aprendizaje de la decepción o del desencanto:

Desencanto, porque nuestras idealizaciones no se corresponden con el mundo tal y como es o nos lo representamos o lo experimentamos a través del modo como nos trata la vida. Desencanto, porque ni el dominio de la razón, como tampoco el de la cultura, son suficientes para poner freno a la barbarie y a las pasiones desmedidas (Bárcena, 2012a, p. 98). 
En las narrativas de los tres escritores presentados, las formas de narrar la violencia política posibilitan, desde la mirada subjetiva, el desplazamiento de lo singular a lo plural, puesto que en ellas, más allá de una experiencia individual, se construyen símbolos en los que pueden encontrarse lectores de muchas latitudes, quienes relacionan elementos de una historia compartida, comparable con otras, aunque no equivalente. Del mismo modo, en la identificación de las fuentes de la violencia, las narrativas rehúyen a la individualización y al señalamiento de culpables con nombre propio. Con estas dos características, vistas en clave de los trabajos de la memoria, estas narrativas permiten situar las posibilidades de construcción de una memoria ejemplar que, en términos de Todorov (2000), supera el pasado intransitivo, que no se deja interpelar por el presente, que se torna vengativo y veta los nuevos sentidos.

Por otra parte, el ámbito de lo íntimo, lo cotidiano y lo familiar en el que son puestos a vivir los personajes de las obras analizadas, en diálogo con sus contextos sociales, se constituye en el primer escenario de comprensión de los sujetos (tanto personajes, niños en su mayoría, como lectores) en "la realidad histórica de su ser" (Gadamer, 1991, p. 344). Para el caso, desde perspectivas que, más allá de los usos políticos, poco han sido consideradas: de los niños, los jóvenes y los ancianos.

Arciniegas, Buitrago y Montaña recurren a la ficción para construir símbolos y ofrecer "modelos de comprensión que nos permitan dar un orden a la confusión de la realidad" (Muñoz, 2008, p. 44), en una palabra, imaginar. Y la imaginación, dicho sea de paso, se constituye en el elemento de la memoria vuelta hacia el pasado, su resignificación en el presente y la configuración de horizontes de futuro que, sin desprenderse de su herencia, pueden ser distintos. Se entiende, entonces, que en la idea de la herencia que se recibe está presente, a su vez, la idea del legado que se transmite.

Más allá de erigirse como una herramienta didáctica en el aula para la transmisión de un conjunto de valores sociales legítimos, la literatura se torna en espacio necesario para la configuración de referentes y para dotar de nombres, mundos que, aunque reales para sí o para otros, el lector —en el proceso de lectura - pone afuera y es capaz de comprenderlos en el plano imaginario y regresarlos a la vida dotados de un sentido distinto.

\section{Conclusiones}

Con el propósito de plantear aproximaciones a los modos como se configura el entre generacional en la literatura infantil colombiana, el artículo partió de las preguntas por las formas de narrar la violencia política en estas producciones, por los sentidos del pasado que se 
ponen en juego en estas narrativas y por las maneras como los vínculos generacionales permean la escritura de los autores. Para ello se llevó a cabo el acercamiento a las obras de Triunfo Arciniegas, Jairo Buitrago y Francisco Montaña. El análisis se planteó en relación con dos aristas: las herencias recibidas y los legados por transmitir, y las formas de narrar la violencia política.

Respecto de la primera arista es posible concluir, por una parte, que en las herencias recibidas por las generaciones anteriores operan las apuestas por el sostenimiento o el cambio del orden social y las condiciones de violencia política que emergieron en el marco de una democracia restringida desde la década de los setenta; $y$, por otra parte, que en los legados por transmitir a las nuevas generaciones se ponen en juego miradas hacia el pasado vergonzante desde los referentes propios de los escritores en el presente. Sobre la base de este inter/entre generacional los escritores construyen en sus obras apuestas para la transformación del porvenir en las que la mirada hacia el pasado forma parte fundamental por cuanto este es revisitado y resignificado.

En relación con la segunda arista es posible colegir que, en la lectura de las matrices discursivas y el tipo de narrativas construidas por los autores, así como en las formas de narrar la violencia política que se configuran en las obras revisadas, se articulan sus apuestas éticas y políticas: construyen sus relatos a partir de las voces de los niños, pocas veces escuchadas en la esfera pública; optan por una narrativa intimista, para mostrar los impactos de la violencia política en la vida cotidiana; se aproximan a la subjetividad y a sus reconfiguraciones y exploran los sentimientos; construyen símbolos a través de la alegoría y la metáfora que permiten dilucidar sentidos sobre lo incomprensible y lo inefable.

Con todo, la literatura infantil colombiana referida a temáticas asociadas a la violencia política, entendida como artefacto cultural, participa del mundo social y político y, en esta vía, ofrece posibilidades de ruptura con el pasado vergonzante y de construcción de sentidos distintos respecto de la consolidación de lo político como espacio posible para el conflicto y la diferencia sobre la base del respeto a la vida.

Con base en la perspectiva de análisis planteada y para continuar ampliando las comprensiones del entre generacional en la literatura infantil, valdría la pena auscultar en las configuraciones generacionales en el universo de las obras a través del análisis de los personajes y la manera como se tejen sus vínculos. En este es posible observar modulaciones de lo infantil y de los modos de ser niño en su relación con el adulto y los coetáneos. También se estima necesario explorar el inter/entre generacional que se da en el proceso de recepción del texto, bajo el entendido de que los libros para niños convocan a lectores de todas las edades. 


\section{Referencias}

Arciniegas, T. (2015, 18 de septiembre). Los días del asombro / A manera de prólogo. En De otros mundos [Blog]. Recuperado de http://triunfo-arciniegas.blogspot.com/2015/09/los-dias-del-asombro-manerade-prologo.html.

Arciniegas, T.; Burgos, R.; Echeverri, J.; Jaramillo, D.; Lozano, P.; Macías, L. F.; Merino, J. F.; Reyes, Y.; Salcedo, A. (2014). Los días del asombro: poética de las ciudades. Bogotá: SM.

Arciniegas, T. y Álvarez, D. (2005). El árbol triste. México: SM.

Arciniegas, T. y Álvarez, D. (2009). El árbol triste. Bogotá: sM.

Arciniegas, T. y González, H. (2011). El último viaje de Lupita López. Bogotá: SM.

Arciniegas, T. y Soacha, Ó. (2011). El rabo de Paco. México: Fondo de Cultura Económica.

Arendt, H. (1996). La crisis de la educación. En Entre el pasado y el futuro: ocho ejercicios sobre la reflexión política (pp. 185-208). Barcelona: Península.

Asesinatos de líderes sociales: una crisis humanitaria. (2018, 6 de julio). En Verdad Abierta. Recuperado de https://verdadabierta.com/asesinatos-de-lideres-sociales-una-crisis-humanitaria/.

Bárcena, F. (2012a). El alma del lector. La educación como gesto literario. Bogotá: Babel Libros.

Bárcena, F. (2012b). Entre generaciones. Notas sobre la educación en la filiación del tiempo. En M. Southwell (comp.), Entre generaciones. Exploraciones sobre educación, cultura e instituciones. Rosario: Homo Sapiens.

Buitrago, J. y Betancourt, M. (2017). Retrato de niños con bayonetas. Bogotá: Panamericana Editorial.

Buitrago, J. y Blanco, D. (2015a). Un diamante en el fondo de la tierra. Santiago de Chile: Amanuta.

Buitrago J. y Guevara, S. (2017). Los irlandeses. Bogotá: Babel Libros.

Buitrago, J. y Mayorga, J. C. (2016). Gabriela camina mucho. Bogotá: Ministerio de Educación.

Buitrago, J. y Yockteng, R. (2008). Camino a casa. México: Fondo de Cultura Económica.

Buitrago, J. y Yockteng, R. (2009). Eloísa y los bichos. Bogotá: Babel.

Buitrago, J. y Yockteng, R. (2010). El primer día. Bogotá: Alfaguara.

Buitrago, J. y Yockteng, R. (2015b). Dos conejos blancos. México: Castillo.

Espinosa, P. (2013, 11 de julio). Entrevista a Jairo Buitrago. En Fundación La Fuente. Recuperado de http://www.fundacionlafuente.cl/entrevista-a-jairo-buitrago/. 
Gadamer, H.-G. (1991). Verdad y método. Salamanca: Sígueme.

García, L. (2016). Literatura infantil y violencia política: itinerarios de lecturas sobre las memorias narrativas del Cono Sur. Perífrasis. Revista de Literatura, Teoría y Crítica, 7 (13), 83-98.

Herrera, M. C. y Pertuz Bedoya, C. (2016). Educación y políticas de la memoria. Por una pedagogía más allá del paradigma del sujeto víctima. Bogotá: Universidad Pedagógica Nacional.

Krips, V. (2000). The presence of the past. Memory, heritage, and childhood in postwar Britain. Nueva York y Londres: Garland Publishing.

"La paz nos está costando la vida": Marcha Patriótica. (2017, 17 de noviembre). En Verdad Abierta. Recuperado de https://verdadabierta.com/ la-paz-nos-esta-costando-la-vida-marcha-patriotica/.

Logie, I. y Williem, B. (2015). Narrativas de la postmemoria en Argentina y Chile: la casa revisitada. Alter/nativas, 5, 1-25.

Machado, A. M. (2018). Punto de fuga. Bogotá: Babel Libros.

Marín, G. (2012). Jairo Buitrago, autor infantil: "mis libros son alegorías políticas". En La Tercera. Recuperado de http://diario.latercera.com/ edicionimpresa/jairo-buitrago-autor-infantil-mis-libros-son-alegorias-politicas/\#.

Matiz, A. (2018, febrero 12). Jairo Buitrago, escritor e ilustrador [entrevista]. En La Crónica. Recuperado de https://www.cronicadelquindio.com/noticia-completa-titulo-jairo-buitrago-escritor-e-ilustrador-nota-117973.

Meirieu, P. (1998). Frankenstein educador. Barcelona: Laertes.

Montaña, F. (2012). No comas renacuajos. Bogotá: Babel Libros.

Montaña, F. (2013). El gato y la madeja perdida. Bogotá: Alfaguara Juvenil, Universidad Nacional de Colombia.

Montes, G. (2017). Buscar indicios para construir sentido. Bogotá: Babel Libros.

Muñoz Molina, A. (2008). La disciplina de la imaginación. Bogotá: Asolectura.

Redondo, P. (2012). "Entre" generaciones: infancia, tiempo y política. En M. Southwell. (comp.), Entre generaciones. Exploraciones sobre educación, cultura e instituciones. Rosario: Homo Sapiens.

Ricoeur, P. (2000). La memoria, la historia, el olvido. Buenos Aires: Fondo de Cultura Económica.

Rosero, J. (2010). Las cinco relaciones dialógicas entre el texto y la imagen dentro del álbum ilustrado. Bogotá: S. E.

Sánchez, C. (2009a). El largo camino de la paradoja a la ironía: el humor en Triunfo Arciniegas. En T. Arciniegas. Cuadernos de literatura infantil colombiana. Serie Autores (pp. 16-25). Bogotá: Biblioteca Nacional de Colombia. 
Sánchez, C. (2009b). Entrevista realizada por Carlos Sánchez Lozano. Los cuatro veintes de Triunfo Arciniegas. En T. Arciniegas. Cuadernos de literatura infantil colombiana. Serie Autores (pp. 53-60). Bogotá: Biblioteca Nacional de Colombia.

Strasser, C. (2013). ¿Quién es "un preso político"?-Una definición. En Sociedad Internacional para los Derechos Humanos (SIDDHH). Recuperado de http://www.derechos-humanos.info/home/ quien-es-un-preso-politico-una-definicion/.

Todorov, T. (2000). Los abusos de la memoria. Barcelona: Paidós. 